\title{
Espaço e sociedade um paradoxo: a cidade
}

É desnecessário afirmar que a apropriação do espaço terrestre é um dos maiores desafios que se impõe ao homem do século XX e, com muito maior peso, vai impor-se ao homem do século XXI. Uma das manifestações mais contundentes dessa apropriação tem sido, sobretudo depois da revolução industrial, o crescente e assombroso processo de urbanização. As estatísticas indicam que, até o final deste século, cerca de 80 a $90 \%$ das pessoas que povoarão o planeta viverão nas cidades. Apesar da grandiosidade dos números, as crônicas das 'patologias urbanas' (criminalidade por exemplo) cuidam de transmitir aos homens um profundo sentimento de insegurança. E esta insegurança resulta da violência que se observa nas cidades, seja pela escassez de certos equipamentos e serviços - que interferem diretamente na qualidade de vida das populações - , seja pela incapacidade do Estado em gerenciar os monstros urbanos que se vem formando (a quase falência de Nova York e das cidades brasileiras, que insistentemente clamam por maiores recursos, comprovam isso) e, ainda, seja pela demonstração flagrante da probreza, denunciada de forma brutal pelas cidades ostentando em seu bojo subabitação, favela, menor abandonado, desemprego, marginalidade, prostituição.

Assim instalada a cidade se identifica por intermédio de paradoxo, pois também se constitui no derradeiro 'porto de esperança' para levas e levas de migrantes de todas as classes e de todas as rendas, que nela se realizam, se divertem e trabalham.

A apropriação do espaço apresenta ainda outros paradoxos: o urbano, que sempre censurou o tradicionalismo e o 'provincialismo' rural, hoje no entanto tem como maior aspiração - ainda que citadino - viver no campo. Se as levas de migrantes enfeiam a cidade, a expansão urbana depreda e descaracteriza o campo e a zona rural.

Como se vê, a questão é complexa. No entanto, as abordagens que se fazem aos aspectos referentes à apropriação do espaço são sempre setorizado. Esquece-se que o espaço, sua produção e apropriação são produtos e reflexos da sociedade. O espaço não é passivo, inerte. Ele é antes de tudo criação social, portanto dinâmica. O seu tratamento correto só pode ser globalizante e nunca setorial. Quem tratar o espaço como 'a zona produtora de café ou de cana', o 'transporte urbano', o 'zoneamento urbano', o 'sistema viário', o 'saneamento básico', 'violência', de forma linear e estanque, incorre num sério e grave erro científico, metológico e mesmo filosófico. São o homem e a sociedade, em suas múltiplas dimensões, que criam e se apropriam do espaço. Cada homem e cada sociedade definem e se apropriam do seu espaço. E é assim que o espaço tem sido manipulado, desde a formação dos estados modernos, envolvendo, inclusive, a própria disputa entre os grupos sociais no interior de uma cidade (veja-se, por exemplo, em São Paulo a questão dos corretores de comércio e de transporte, a invasão de terrenos urbanos etc.).

No caso do Brasil, a questão do espaço se torna ainda mais complexa e premente por diferentes razões, a saber: a) pela continentalidade do território brasileiro; b) pelo ritmo e características da nossa ocupação territorial; c) pelo ritmo e selvageria do 
nosso processo de urbanização; d) pelas características específicas do nosso processo histórico e de desenvolvimento; e) pela ausência de uma teoria sobre o espaço em geral e sobre a urbanização em particular; e f) pela necessidade de envolver os cidadãos nesse debate indispensável e fundamental, para as gerações futuras que receberão e viverão o espaço que hoje produzimos.

\section{Então, como tratar o espaço?}

Milton Santos (1979) focaliza de forma pertinente a questão quando propõe a divisão do trabaIho social corno uma nova pista para o estudo da organização espacial e da urbanização nos países subdesenvolvidos. "O espaço geográfico, incluindo as cidades, uma realidade em processo permanente de transformação, tem sido estudado por grande número de disciplinas: geografia, economia regional e urbana, sociologia urbana, urbanismo, arquitetura, análise regional, planificação urbana e regional, etc. Cada uma dessas disciplinas adotou um enfoque particular e, também, dir-se-ia, uma epistemologia particular."

Mesmo o vocabulário é específico. Tais particularismos de percepção e de linguagem conduzem, muitas vezes, a considerar apenas uma parte da realidade espacial em vez de levar em conta a realidade toda. Essa orientação, aliás, se aprofunda à medida que as especialidades crescem e constitui, por isso, uma dificuldade suplementar para a construção de uma teoria geral do espaço, uma linguagem comum tanto do ponto de vista teórico, quanto do ponto de vista das realizações de ordem prática.

As explicações do fenômeno de urbanização variam. Todas, porém, giram em torno de fatores como o comportamento demográfico, o grau de modernização e de organização dos transportes, o nível de industrialização, os tipos de atividades e relações que mantêm com os grupos sociais envolvidos, a criação e retenção local do valor adicionado, a capacidade de local para guardar uma maior e menor parcela da mais-valia gerada, o grau de redistribuição da renda entre os produtores, os efeitos diretos ou indiretos da modernização sobre a política, a sociedade, a cultura e a ideologia.

A cada momento histórico, a combinação desses fatores nos dá o nível da urbanização e sua 'geografização' nos dá o padrão de distribuição das cidades, a forma da sua rede urbana, assim como o "perfil urbano de um país, isto é, o tamanho respectivo das cidades dentro de um sistema".

É nessa 'geografização' que se impõe o problema da produção do espaço, dos objetos que povoam o espaço: portanto, das formas. Os objetos geográficos são formas. Por isso, a todo momento com a História se criam novas formas para responder a novas e precisas necessidades, ao mesmo tempo em que velhas formas mudam de função, dando lugar a uma nova geografia construída com veIhos objetos.

Qualquer que seja o instante em que as examinemos, as formas tomadas isoladamente representam uma acumulação de tempo; e sua compreensão, desse ponto de vista, depende do entendimento do que foram as divisões do trabalho pretendido. Seu valor sistêmico, porém, que é seu valor atual e real, depende da divisão do trabalho atual. A sociedade evolui no tempo e no espaço que é simultaneamente contínuo, descontínuo e irreversível. Tomado isoladamente, tempo é sucessão, enquanto espaço é acumulação - justamente uma acumulação de tempos.

Assim, um estudo e um debate sobre o espaco poderia tratar do tempo histórico concreto (presente, passado e futuro) e das utopias (realizadas e realizáveis). No primeiro caso, vinculando sobretudo espaço e meios de produção; no segundo, assumindo a cidade como representante de uma utopia por excelência. Platão, Thomas More, Rabelais ou Fourier deram às suas utopias a forma de uma cidade, no sentido geográfico do termo, isto é, um território habitado por um conjunto organizado de seres humanos, cujas dimensões variam segundo os autores, desde a 'cidade-estado' até a 'microcidade' - da abadia ao phalanstère.

Se se considerar a utopia (Friedman, Yona; 1979) como um projeto que aumentará a satisfação de um grupo de seres humanos, a cidade se ressalta como sendo esse projeto. Contudo, o que se conhece hoje é uma degradação dessa utopia chamada cidade. O que são, por exemplo, as favelas, os condomínios fechados, os policiamentos de quarteirão?

Um outro aspecto importante a ser sublinhado: a cidade e o campo se constituem num espaço de vida para todos. Neste espaço, cada um se apropria e se assenta: o motoqueiro, o hippie, a dona de casa, o tecnocrata, o ministro, os governantes, o punk. Cada um vivencia e percebe o espaço de uma maneira. Mas seria esse o espaço global, o espaço que devemos debater?

Nesse sentido, o que é feito da Carta de Atenas, que até hoje pontifica sobre a organização urbana, apesar das críticas que lhes são dirigidas? E as novas propostas de vida urbana, tanto no campo (que também se transforma), quanto na cidade? O funcionalismo, postura tão apregoada por eméritos urbanistas, ainda terá respostas para o desafio urbano atual? Quais os novos caminhos da política urbana? Qual será o espaço da escassez, fenômeno que já caracteriza a sociedade moderna? 
Os brasileiros em geral, e os cientistas do urbano em particular, têm muito o que refletir a res"peito de todas essas questões.

É desnecessário apontar o esforço desenvolvido por núcleo de pesquisadores, disseminados por este Brasil afora, que se empenham por formular um projeto de pesquisa que auxilie no conhecimento do processo de urbanização brasileira. Até aqui, porém, esse processo tem sido estudado numa perspectiva metodológica que, de forma redundante e mesmo repetitiva, se apóia em metodologias importadas. É escusado 'reprisar' esse fato. Apenas a título de ilustração, e como sugestão de pesquisa, é interessante examinar quando e em que contexto da história surgem na primeira metade do século XIX na Alemanha a teoria da centralidade, com Von Thunen, Christaller e outros, e, na França, a teoria da polarização, com François Perroux e Jacques Boudeville. Nós, brasileiros, até hoje bebemos nessas fontes. Contudo, é importante se perguntar o que é que essas teorias pretendiam explicar: o quê? para quê? por quê?

Espaço é História, pois é uma acumulação de tempos, manifesta inclusive por meio da forma. 0 espaço (a cidade em particular) é uma linguagem da História. Ingênuo pensar que o espaço urbano (urbano e rural) é um mero suporte dos homens e de suas atividades. O espaço é social.

Tais conjunturas, lançadas au hasard, significam simplesmente a necessidade urgente que temos de formular melhor o urbano, especialmente o urbano brasileiro. Esse objeto complexo de reflexão carece de uma explicação mais acurada. Não é mais possível aceitar explicações descritivas sobre um espaço passivo - um espaço segmentado, reduzido a expressões e formulações simplistas demais para uma questão complexa. No caso do urbano, em particular nos países pobres, as formulações são eivadas de um colonialismo explicitado na formulação de 'modelos'. Os modelos, que tão amplamente são difundidos entre nós, se constituem num dos rancos mais odiosos dessa postura. E quantos modelos urbanos não foram importados de Harvard, Londres e Paris sem a mais ligeira preocupação crítica?
Numa perspectiva de aprofundar a crítica, gerar polêmicas e fazer caminhar o processo de conhecimento sobre a produção e a apropriação do espaço, em especial nos países do Terceiro Mundo, propomos que o estudo do urbano considere, pelo menos, quatro categorias analíticas: o capital e sua estratégia de reprodução, coisificada no espaço; o Estado pelas mediações que realiza e pelo instrumental que gera, implicando diretamente na produção e apropriação do espaço (sistemas de planejamento, legislação urbana, políticas urbans etc. l; a renda da terra, onde se assume o espaço como uma mercadoria e que, portanto, o investir nele é agregar-lhe valor (neste sentido fica inclusive mais fácil de entender e delimitar o perímetro da atuação insistente do Estado e do grande capital na produção do espaço - quantos projetos iá tiveram, por exemplo, a avenida Paulista, a Sé e o Anhangabaú em São Paulo?); e finalmente, a disputa entre os grupos sociais, manifestada na cidade sob múltiplas formas: violência, invasão, resistências, apropriações 'indébitas' de espaços (do público pelo privado e vice-versa).

Desse ponto de vista, o corte para o estudo da cidade é outro diferente daquele tradicionalmente usado. A cidade, então, não mais desempenha funções, mas realiza contradições.

Essa e outras novas pistas para o estudo da urbanização brasileira difundidas pelo país merecem ser examinadas e discutidas.

É preciso não esquecer a lição de que as verdadeiras revoluções não se produzem com armas, mas com idéias, com teorias. E o processo de libertação brasileira, no que tange à questão urbana, apenas se inicia.

\section{Bibliografia}

SANTOS, Milton. Espaço e sociedade. São Paulo, Vozes, 1979. p.37.

FRIEDMAN, Uona. Utopies réalizables. Paris, Ed. Union Génerale d'Editions, 1979. p. 229. (Collection 1018, n. 997). 
